\title{
2308 浮選の立場からみた黄鉄鉱の結晶構造について
}

\author{
東京大学工学部教授・工博 今 泉 常 正(正会員) \\ 東京大学工学部助教授 . 工博 井 上 外 志 雄(正会員) \\ 東京大学工学系大学院学生 ○梄 原常栄(正会員)
}

\section{1. 緒一言}

著者らは，過去におらて各種の石炭の浮選速度に関す 石研究を行ない, 石炭の化学構造が石炭化度により偏倚 し，そのため浮選特性が変化することを確かめた ${ }^{1) 2) ~}$ 乙の構造偏倚の現象は金属鉱物におらても，その変化の 幅の差こそあれしばしばみられるものであり；浮選にお けるこの種の問題の重要性が一般に注目を集めつつある。 とくに黒鉱の選鉱においては，その中に含をれる、黄鉄鉱 の挙動が，“浮選操業にきわ的て複雑かつ重要な影響をお 上隹している事実が近年認識されてきた。例えば酸化速 度の遅速，浮遊性の大小など，同じ黄鉄鉱でありながら 種々性質の異なるものが湿在しており，てれが浮選操業 の安定性を著しく阻害しているととが強調されている。 黄鉄鉱自体，生成条件によって結晶構造を異にし，電気 的性質をはじめとして種々の物性にある幅があるととは 鉱物学的にはある程度知られている3

著者らは，乙の問題の黑鉱選鉱の上に占的る重要性に 着目し, 浮選の立場から黄鉄鉱の結晶構造を調べる研究 に着手した。すなわち黒鉱鉱床中の黄鉄鉱試料につんて, X線回折にようて内部構造を, 光学影微鏡, 位相差顕微 鏡，電子顕微鏡によって表面構造を，示差熱分析，熱天 科法により構造の熱的安定性をしらべるとともに, 電気 泳動法によりら電位を測定し, 前掲の結晶構造との関係 を考察した。このよらなデータに基いて黄鉄鉱の結晶構 造と浮遊性との関係を明らかにするととを目的としてさ らに研究を進めている。

\section{2. 実 験 試 料}

実験試料としては，花岡鉱山堂屋敷鉱床の坑内上り採 取した 40 試料を光学顕微鏡で観察し，その中より代表

第 1 表 ‘試料の採取位置（堂屋敷鉱床内）

\begin{tabular}{|c|c|c|}
\hline No & & 取 。 \\
\hline 1 & $\mathrm{Py}-\mathrm{O}$ & 珪化帯反近々 \\
\hline 3 & $\mathrm{Py}-\mathrm{O}$ & 硫化鉣体上部 \\
\hline 6 & $\mathrm{Py}-\mathrm{O}$ & 石管体周縁部 \\
\hline 7 & $\mathrm{Gp}-\mathrm{Py}-\mathrm{O}$ & 硫化江富む石苇体 \\
\hline 11 & $\mathrm{Py}-\mathrm{O}$ & 珪質硫化錥付近 \\
\hline 12 & $\mathrm{Py}-\mathrm{O}$ & 下盤の石骨体に近く，石骨を含む \\
\hline 14 & $\mathrm{Py}-\mathrm{O}$ & 硫化鉱体中央部やや上位 \\
\hline 15 & $\mathrm{Py}-\mathrm{O}$ & 硫化鉱体中央部 \\
\hline 17 & 粉状 $\mathrm{Y}-\mathrm{O}$ & 上盤の近く，粘土質 \\
\hline 20 & $\mathrm{Py}-\mathrm{O}$ & 上盤の近く \\
\hline
\end{tabular}

$\mathrm{Py}-\mathrm{O}$ : 硫化鉱体 $\mathrm{Gp}-\mathrm{Py}-\mathrm{O}$ : 石骨硫化鉱体 $\mathrm{Y}-\mathrm{O}$ : 黄鉱体

第 2 表 試料の化学分析婊

\begin{tabular}{|c|c|c|c|c|c|c|c|c|c|c|c|}
\hline $\begin{array}{l}\text { 成分 } \\
\text { 은 }\end{array}$ & $\mathrm{Fe}$ & $\begin{array}{r}\text { tot al } \\
\mathrm{S}\end{array}$ & ${ }^{\text {free }} \mathrm{S}$ & $\mathrm{SO}_{4}$ & $\mathrm{Cu}$ & $\mathrm{Pb}$ & $\mathrm{Ca}$ & $\mathrm{B} \mathrm{a}$ & As & $\mathrm{Si} \mathrm{O}_{2}$ & $\mathrm{~s} / \mathrm{Fe}$ \\
\hline 1 & 44.15 & 51.01 & 0.21 & 2.15 & 0.13 & 0.28 & $<0.01$ & $<0.05$ & 0.09 & 0.89 & 1.98 \\
\hline 3 & 44.0 & 50.51 & & & 0.10 & 0.23 & $<0.01$ & $<0.05$ & 0.07 & 0.23 & $\begin{array}{l}1.96 \\
\text {. }\end{array}$ \\
\hline 6 & 44.98 & 51.53 & 0.25 & 4.32 & 0.05 & 0.11 & 0.42 & $<0.05$ & 0.18 & 0.14 & 1.93 \\
\hline 7 & 30.42 & 41.18 & $<0.05$ & 21.40 & 0.03 & 0.31 & \begin{tabular}{|l}
-7.60 \\
\end{tabular} & $<0.05$ & 0.18 & 0.63 & 1.95 \\
\hline 11 & 45.63 & 52.57 & 0.05 & $\begin{array}{r}1.23 \\
\end{array}$ & 0.13 & 0.40 & $<0.01$ & $<0.05$ & $<0.01$ & 0.12 & $\begin{array}{l}1.99 \\
\end{array}$ \\
\hline 12 & 42.37 & 48.12 & $<0.05$ & 0.41 & 0.15 & 0.34 & $<0.01$ & $<0.05$ & 0.08 & 5.29 & 1.97 \\
\hline 14 & 42.67 & & $<0.05$ & & & 0.34 & 0.02 & $<0.05$ & $<0.01$ & 6.99 & 1.99 \\
\hline 15 & 45.87 & 52.74 & $\begin{array}{r}\quad 0.09 \\
\end{array}$ & 2.3 & 0.0 & 0.28 & 0.39 & $<0.05$ & 0.14 & 0.17 & 1.97 \\
\hline 17 & 35.86 & 41.47 & 0.11 & 0.3 & 0.18 & 0.57 & 0.43 & $<0.05$ & 0.38 & 8.87 & 2.00 \\
\hline 20 & 43.32 & 49.40 & 0.08 & 1.59 & 3.61 & - & 0.04 & $<0.05$ & 0.30 & 0.18 & 1.96 \\
\hline
\end{tabular}

Vol. 84 No. $959(' 68-3)$
的な 10 試料を選んで実験に供した。試料の採取位置は 第 1 表飞, 化学分析値就よ゙゙ $\mathrm{S} / \mathrm{Fe}$ (atomic ratio) 壮第 2 表に示す通りである。試料の中には不純物のかな り多いものもあるが，乙れらは試料の組織が緻密で黄鉄

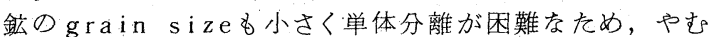
を得ずそのまま供試した。また $\mathrm{S} / \mathrm{Fe}$ 亿関しては，1.93 〜 2.00 範囲のばらつをがあり，理論值より $\mathrm{Fe}$ 過剩の ものが多い。

試料の内部構造をしらべるために行なったX線回折の 結果を第 3 表に要約してある。t t r g e t として Coを用い 311 面について行なった精密測定により $2 \theta_{311}$ を求め, そ の原子網面間距離 $d_{311}$ を算出した。をた $I_{311}$ を規準とし た 111 面, 200 面，210 面，220 面，211 面の相対強 度を求め，表に記した。乙れらの結果をみると， $2 \theta_{311}$ あるんは $\mathrm{d}_{311}$ と $\mathrm{I}_{200} / \mathrm{I}_{311} ， \mathrm{I}_{210} / \mathrm{I}_{311}$ との間にある程度 の相関が認められる。

第3表 試料のX線回折結果

\begin{tabular}{r|c|c|c|c|c|c|c}
\hline No & $2 \theta_{311}$ & $\mathrm{~d}_{311}(\AA)$ & $\mathrm{I}_{111} / \mathrm{I}_{311}$ & $\mathrm{I}_{200} / \mathrm{I}_{311}$ & $\mathrm{I}_{210} / \mathrm{I}_{31}$ & $\mathrm{I}_{220} / \mathrm{I}_{311}$ & $\mathrm{I}_{211} / \mathrm{I}_{311}$ \\
\hline 1 & 66.495 & 1.63141 & 0.392 & 2.29 & 1.22 & 0.547 & 0.920 \\
3 & 66.450 & 1.63251 & 0.403 & 1.64 & 1.20 & 0.538 & 0.885 \\
6 & 66.460 & 1.63249 & 0.406 & 1.73 & 1.20 & 0.568 & 0.786 \\
7 & 66.420 & 1.63258 & 0.369 & 1.66 & 1.02 & 0.477 & 0.846 \\
11 & 66.416 & 1.63258 & 0.418 & 1.51 & 1.07 & 0.536 & 0.810 \\
12 & 66.425 & 1.63256 & 0.426 & 1.61 & 1.16 & 0.564 & 0.857 \\
14 & 66.406 & 1.63261 & 0.368 & 1.34 & 1.03 & 0.514 & 0.827 \\
15 & 66.421 & 1.63257 & 0.334 & 1.42 & 1.09 & 0.526 & 0.798 \\
17 & 66.425 & 1.63256 & 0.384 & 1.94 & 1.14 & 0.513 & 0.860 \\
20 & 66.406 & 1.63261 & 0.350 & 1.46 & 0.987 & 0.483 & 0.787 \\
\hline
\end{tabular}

\section{3. 表面の結晶構造の研究}

浮選においては鉱物の内部よりはむしろ表面が重要な 役割を果すととは周知の事実であるが，その表面構造は 鉱床生成条件により著しい相違を示し，また結晶面によ らてもその反応性がことなるととが指摘される。そのた

第 4 表 光学顕微鏡観察結果

\begin{tabular}{|c|c|c|c|c|c|}
\hline No. & $\begin{array}{l}\text { 研摩面数 } 1 \\
\text { 状態 }\end{array}$ & $\begin{array}{l}\operatorname{grain}^{* 2} \\
\text { 粒 度 }\end{array}$ & $\begin{array}{l}\text { porosi ty } \\
\emptyset \text { 程 度 }\end{array}$ & $\begin{array}{ll}\text { pit } & \sigma^{* 3} \\
\text { 多 } & \text { 少 }\end{array}$ & 備： \\
\hline 1 & s.s & 1 & $\mathrm{~m}$ & $\mathrm{~m}$ & \\
\hline 3 & $\mathrm{~s}$ & 1 & $f$ & $\mathrm{f}$ & \\
\hline 6 & s.s & $\mathrm{m}$ & $\mathrm{m}$ & $\mathrm{m}$ & \\
\hline 7 & n.s & s & $m$ & $\mathrm{v}$ & コロホーム \\
\hline 11 & $\mathrm{~s}$ & $\mathrm{~m}$ & $f$ & $\mathrm{f}$ & \\
\hline 12 & s.s & $\mathrm{s}$ & $\mathrm{v}$ & $\mathrm{m}$ & barite \\
\hline 14 & $\mathrm{~s}$ & $\mathrm{~m}$ & $\mathrm{~m}$ & $\mathrm{~m}$ & chal copyrite \\
\hline 15 & $\mathrm{~s}$ & 1 & $\mathrm{f}$ & $\mathrm{m}$ & \\
\hline 17 & n.s & $\mathbf{s}$ & $f$ & $\mathrm{~m}$ & charite \\
\hline 20 & $\mathrm{~s} . \mathrm{s}$ & $\mathrm{m}$ & $\mathrm{v}$ & $\mathrm{m}$ & $\left\{\begin{array}{l}\text { bar te } \\
\text { chal copyr i te }\end{array}\right.$ \\
\hline
\end{tabular}

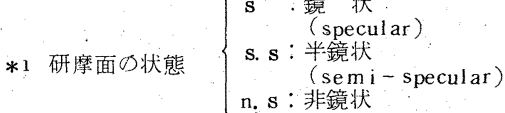

$$
\begin{aligned}
& \text { (non-specular) } \\
& \text { *2 grain の粒度 }\left\{\begin{aligned}
1 & \vdots \text { l arge } \\
\mathrm{m} & \vdots \text { medium } \\
\mathrm{s} & \text { small }
\end{aligned}\right. \\
& \text { *3 porosityの程度 } \mathrm{v}^{\mathrm{v}} \text { ： very many } \\
& \text { pit 勿多少 }\left\{\begin{array}{c}
m \\
\mathrm{f}
\end{array}\right. \text { : mediu }
\end{aligned}
$$


め各試料間のみならず，同一試料面内でもミクロ的にみ ると不均一であり，乙れが各表面の物理化学的特性にを わめて大をな意味をもつととが推測でをる。捕収剂が鉱 物表面飞 pat ch 状飞吸着するとい5 PLAKS IN らの研究 結果 $^{4)}$ なともとの事実と関係がありそうである。

この表面構造を理解するために，第 1 亿研摩試料面を 光学顕微鏡で観察し, 結晶成長の状態としての $\mathrm{gra}$ i n size, 表面状態を示す尺度として, ガス放出の跡とみら れる porosityの程度, pitの多少につんて表記したも のが第 4 表である。また表面の反応性を知るために, $\mathrm{HNO}_{3}$ (50\%)で $0.5 ， 1 ， 3$ min. et ching した試料表面から了 セチルセルローズ・フィルムでレプリカをとり，乙れを位相 差顕微鏡で観察し，さらにミク口的構造孛知るために， このフィルムムれーポンを真空蒸着し，Pt-Pdのシャド ーイングをほどとし ${ }^{5)}$, 電子顕徽鏡観察を行なった。乙 の結果を李とめたものが第 5 表である。

第5表 etching.figureの電子顕微鏡による観察結果

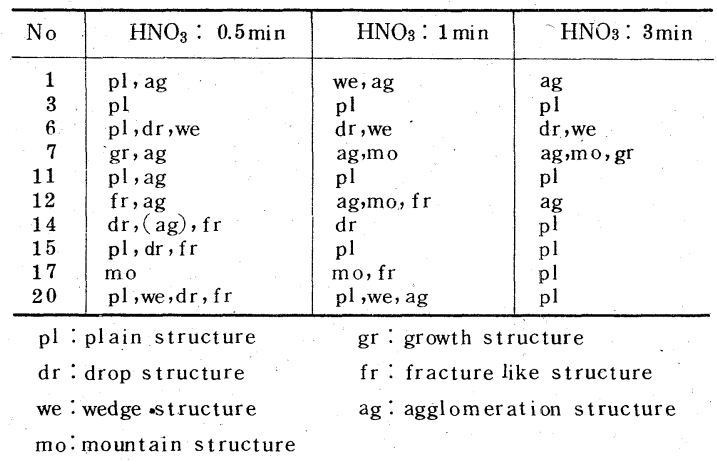

第 4 表と第 5 表とを比較すると, porosity, pi tの 状態が etching 亿対する反応性をある程度示している ととが分る。etching figureの観察から, 一見平滑 な面も多くのgrainの集合体であるとと, agglomeration structure ( a g ) のよら飞時間とともに e t ching の進む ものと, mountain st ructure (mo) のよ5にかえって平滑 化の傾向に進むものがあるとと等が分る。

をた粒子表面のミク口的状態を観察するために走査型 電子顕微鏡により 2 次電子像を観察し，2，3の知見を 得た。

\section{4. $\zeta$ 電位の測 定}

以上のような結晶構造をもつ黄鉄鉱が電解質溶液中で らかなる電気化学的性質を示すかをしらべるために, 顕 微鏡電気泳動法によるら電位の測定を行なった。 $\mathrm{pH}$ 調整剂として $\mathrm{HCl}-\mathrm{NaOH}$ を用い, 印加電圧 $210 \mathrm{~V}$ (DC)で，Pt-KCl 電極を使用して測定した。その結果， $\mathrm{pH}$ とと電位の関係についてみると, 試料により若干の 相違があるととが認められた。黄鉄鉣は一般に $\mathrm{pH}$ が 6 〜 8 よ高くなると, 表面に酸化皮膜が形成され, $\mathrm{Fe}$.
$(\mathrm{OH})_{3}$ が表面で支配的となるが，酸性側に移行するにつ れ酸化皮膜は溶解し，ついに黄鉄鉱自体が溶解するとい われている。また $\mathrm{Fe}(\mathrm{OH})_{3}$ 表面では,

$$
\begin{aligned}
& \mathrm{Fe}(\mathrm{OH})_{3}(\mathrm{~S})+\mathrm{H}^{+}=\mathrm{Fe}(\mathrm{OH})_{2}^{+}(\mathrm{S})+\mathrm{H}_{2} \mathrm{O} \cdots \cdots \text { (1) } \\
& \mathrm{Fe}(\mathrm{OH})_{3}(\mathrm{~S}) \quad=\mathrm{Fe} \mathrm{O}_{2}^{-}(\mathrm{S})+\mathrm{H}^{+}+\mathrm{H}_{2} \mathrm{O} \quad \cdots \text { (2) }
\end{aligned}
$$

の反応が叔こると報告されている ${ }^{6}$ 。

$\zeta$ 電位の結果から，等電点 $(\mathrm{ZPC})$ と $\mathrm{S} / \mathrm{Fe}$ の間には関 連が認められ， $\mathrm{S} / \mathrm{Fe}$ が小さくなるにつれ，ZPCは大と なる傾向がみられる。乙れはSの欠陥あるいは $\mathrm{Fe}$ ，過剩 のため黄鉄鉱の表面が $\mathrm{n}$ 型半導体の性質を示し, 電子濃 度が増加し, $\mathrm{H}^{+}$a c ceptorとしての作用が強化され(1)式 の反応が右に進むためではないかと想像される。

第6表 $\mathrm{S} / \mathrm{Fe}$ と等電点との関係.

\begin{tabular}{c|c|c|c|c|c}
\hline 試料 No. & 1 & 14 & 11 & 12 & \multicolumn{1}{c|}{3} \\
\hline $\mathrm{S} / \mathrm{Fe}$ & 1.98 & 1.99 & 1.99 & 1.97 & 1.96 \\
$\mathrm{ZPC}$ & 6.45 & 6.55 & 6.80 & 7.00 & 7.40 \\
\hline
\end{tabular}

5. 結

言

花岡鉱山堂屋敷鉱床産の黄鉄鉣試料につ々て, 化学組 成, 結晶内部構造, 表面構造和よびと電位を調べ，乙れ ら相互間の関係につんて研究した。さらにこれらの試料 について浮選試験を行索い, 浮遊性との関連を明らかに するとともに, 結晶面による反応性の差異についてのよ り詳細な調査, 走査型電子顕徽鏡に上る粒子表面の電子 分布の観察などを通して, 今後研究を進めて行きたいと 考えている。

李た本実験試料と別に採取した花岡鉱山堂屋敷選鉱工 場のセミバルク浮選系の各フロス和よびテーリングの試 料につんて, X線回折を行なった結果, 浮選速度とX線 回折線の強度比との間にある種の関係があるととがわか つた。このデータについては現在さらに解析を進めてい る。

\section{参考 文 献}

1）今泉常正. 井上外志雄・楢原常栄: 石炭の浮選特性飞ついて。 選炭, 15 巻, 80 号, (1965 年 6 月), $387 \sim 388$.

2）今泉常正·井上外志雄・楢原常栄：石炭の浮選特性几関する速 度論的研究—之く江石炭化度との関係, 燃料協会誌, 44 巻, 464 号, ( 1965 年 12 月), $830 \sim 837$.

3）をとえば F. G.SMITH : Variation in The Properties of Pyrite.The American Mineralogist, 27, 1 (1942), 1-92.

4). I. N. PLAKS IN and R. Sh. SHAFEEV : Influence of Surface Properties of Sulphide Minerals on Adsorption of Flotation Reagents. Bulletin of The Institute of $\mathrm{M}$ ining and Metallurgy, №.680, ( July 1963) 715 721.

5）田島義信：電子顕微鏡試料の調整法. 表面, $2,(1964$ 年 10 月) $\quad 54 \sim 57$.

6) А.А. Аърамов : Влияние рН1 на Состояние Говсрхности Пирита. Цветньіе Металльі №. 12. (1965) 30 33. 